\title{
Photoelectrochemical Behavior of PEDOT/Nanocarbon Electrodes: Fundamentals and Structure-Property Relationships
}

\author{
Attila Kormányos, ${ }^{\dagger,+}$ Dorottya Hursán, ${ }^{\dagger, \ddagger}$ and Csaba Janáky ${ }^{*},+\neq \odot$ \\ †MTA-SZTE "Lendület" Photoelectrochemistry Research Group, Rerrich Square 1, Szeged H-6720, Hungary \\ ${ }^{\ddagger}$ Department of Physical Chemistry and Materials Science, University of Szeged, Rerrich Square 1, Szeged H-6720, Hungary
}

Supporting Information

ABSTRACT: In this study, we investigated the photoelectrochemical behavior of poly(3,4-ethylenedioxythiophene) (PEDOT)/ carbon nanotube (CNT) and PEDOT/graphene nanocomposite photoelectrodes for the first time. Electrodeposition allowed control of both the composition and the morphology (as demonstrated by both transmission and scanning electron microscopy images) and also ensured an intimate contact between the PEDOT film and the nanocarbon scaffold. The effect of CNT and graphene on the photoelectrochemical behavior of the nanocomposite samples was studied by linear sweep photovoltammetry, incident photon-tocharge-carrier conversion efficiency measurements, and long-term

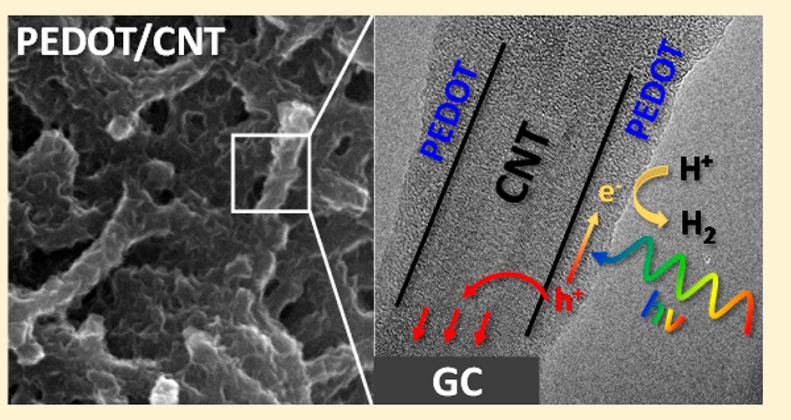
photoelectrolysis coupled with gas-chromatographic product analysis. We demonstrated that the nanocarbon framework facilitated efficient charge carrier transport, resulting in a 4-fold increase in the measured photocurrents for the PEDOT/CNT electrode, compared to the bare PEDOT counterpart. The presented results contribute to the better understanding of the enhanced photoelectrochemical behavior of organic semiconductor/nanocarbon electrode assemblies and might encourage other researchers to study these intriguing hybrid materials further.

\section{INTRODUCTION}

The growing need for carbon neutral energy technologies is a major driver of materials science nowadays. Photoelectrochemical (PEC) solar energy conversion, as a potentially attractive candidate, has gained an increased momentum during recent years. ${ }^{1}$ Although both water-splitting (hydrogen evolution) and carbon dioxide reduction are promising avenues, they both have substantial shortcomings to be addressed. A common virtue of these two processes is that a good photoelectrode has to concurrently fulfill many attributes to drive these reactions efficiently. ${ }^{2}$ These include (i) narrow bandgap, (ii) optimal valence and conduction band positions to drive the desired processes, (iii) good photochemical, chemical, and electrochemical stability over a wide $\mathrm{pH}$ and potential window, (iv) facile charge transfer kinetics, (v) high selectivity toward the formation of the targeted products, (vi) low toxicity, and finally (vii) reasonable production cost. ${ }^{3-5}$ Although several inorganic semiconductors (SCs) ${ }^{6}$ have been tested in these PEC processes, still there is no single material that bears all the above-mentioned properties.

Organic SCs are conceptually different alternatives from their inorganic counterparts. The category of organic SCs can be divided into three main categories: (i) amorphous molecular films, (ii) molecular crystals, and (iii) conducting polymer films (CPs). ${ }^{7}$ Among these groups, here we focus on organic conducting polymers (also called conjugated or semiconducting polymers), which typically behave as p-type semiconductors in their reduced form. 8,9 The first PEC studies were conducted on polyaniline dating back to the mid-1980s, ${ }^{8}$ when small cathodic photocurrents were observed applying negative bias and visible light irradiation. Since then, a few studies were published on this topic, ${ }^{10-17}$ and the PEC behavior was studied also for polypyrrole, ${ }^{9,18}$ poly(3-methyltiophene), ${ }^{19-21}$ substituted polyanilines, ${ }^{10}$ and poly(benzimidazobenzophenantroline). ${ }^{22}$ At the same time, the fundamental understanding of the physicalchemical processes occurring at the irradiated solid/liquid interface is still missing. Among others, these include the light intensity dependence of the photocurrent or the effect of the layer thickness.

PEDOT is a narrow-bandgap $\mathrm{CP}$ and has a broad absorption band in its reduced form (Figure 1A). Moreover, this spectrum overlaps with the solar spectrum, which further highlights the promise of this material in solar fuel generation (Figure 1A). PEDOT has been successfully applied as an electrocatalyst for oxygen reduction and also proven to be a very stable and robust $\mathrm{CP}$ in dark conditions. ${ }^{23}$ PEDOT and its derivatives have already been widely used as hole-transporting materials in dyesensitized and perovskite solar cells, too. ${ }^{24-28} \mathrm{We}$ have confirmed that PEDOT is stable under solar irradiation, and no degradation product was detected by gas-chromatographic

Special Issue: Prashant V. Kamat Festschrift

Received: January 5, 2018

Revised: March 15, 2018

Published: March 15, 2018 

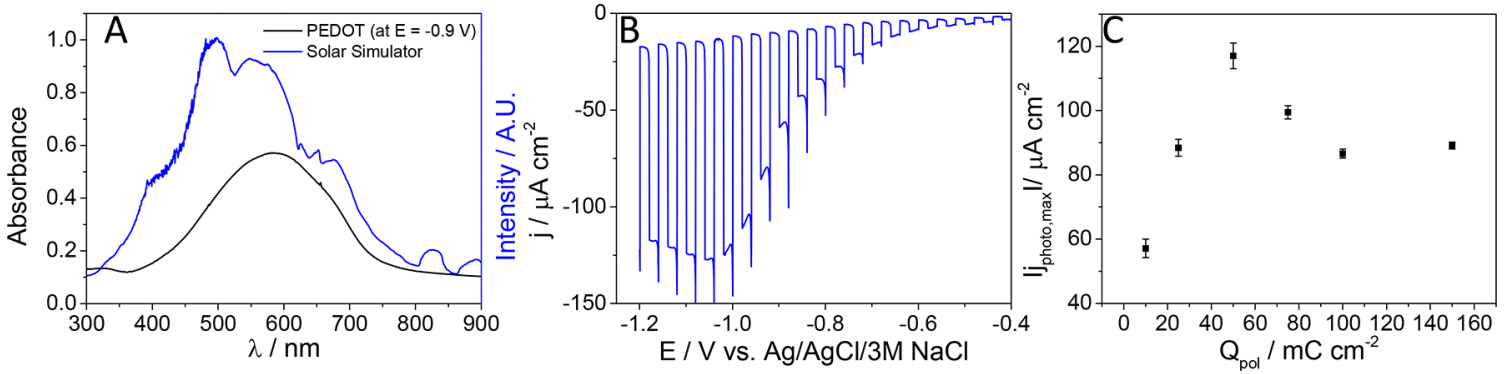

Figure 1. (A) Comparison of the UV-vis spectrum, recorded for a PEDOT layer $\left(Q_{\mathrm{pol}}=25 \mathrm{mC} \mathrm{cm}{ }^{-2}\right)$, at $E=-0.9 \mathrm{~V}_{\text {in }} 0.1 \mathrm{M} \mathrm{Na}_{2} \mathrm{SO}_{4}$ solution, saturated with Ar with the irradiance spectrum of the solar simulator. (B) Photovoltammogram recorded in $0.1 \mathrm{M} \mathrm{Na}_{2} \mathrm{SO}_{4}$ saturated with $\mathrm{Ar}$ for a PEDOT film, electrodeposited with optimal polymerization charge density $\left(Q_{\text {pol }}=50 \mathrm{mC} \mathrm{cm}^{-2}\right)$ on glassy carbon electrode. The sweep rate was kept at $2 \mathrm{mV} \mathrm{s}^{-1}$, while the light-chopping frequency was $0.1 \mathrm{~Hz}$. (C) Maximum photocurrent vs polymerization charge density plot.

analysis (unlike under UV irradiation; see details in Supporting Information and Figure S1). Despite all these facts, there is no comprehensive study in the literature on the PEC behavior of PEDOT.

Unfortunately, CP photoelectrodes suffer from low charge carrier mobility, which results in extensive recombination and thus small photocurrents. Their typical charge carrier mobility values are $0.01-0.1 \mathrm{~cm}^{2} \mathrm{~V}^{-1} \mathrm{~s}^{-1}$ (for poly(3-hexylthiophene) ${ }^{29}$ and 0.045-1.7 $\mathrm{cm}^{2} \quad \mathrm{~V}^{-1} \mathrm{~s}^{-1}$ (for PEDOT:(poly(styrenesulfonate) $).^{30}$ Accordingly, it is not possible to increase the polymer thickness on the current collector to a level where light absorption is sufficient because the photogenerated charge carriers recombine before they could be fully extracted. This statement has been corroborated by the linear sweep voltammograms of PEDOT layers deposited by varying the polymerization charge densities (Figure $1 \mathrm{~B}$ and Figure 1C.). The thickness of the polymer was varied approximately in the 5-75 nm range. ${ }^{31}$ The photocurrent reached its maximum value at $50 \mathrm{mC} \mathrm{cm}$-2 PEDOT loading, without further enhancement by increasing the layer thickness (even a decrease was observed at very high loadings).

A possible way to overcome the limited conductivity of PEDOT is to deposit the polymer on a highly conductive nanostructured scaffold. Thus, the distance that charge carriers have to travel toward the solution and the current collector is reduced. Carbon nanomaterials, such as CNTs and graphene, are attractive candidates in this vein. ${ }^{32,33}$ These nanocarbons have already been combined with inorganic SCs, and the resulting nanocomposites were studied in photocatalysis, photovoltaics, and PEC reactions. ${ }^{34-40}$ Contrastingly, the beneficial properties of $\mathrm{CP} /$ nanocarbon hybrid electrodes have been only exploited in fields outside solar energy conversion, most importantly in supercapacitors. ${ }^{41,42}$ There is only one exception, namely, the family of $\mathrm{CP} /$ fullerene nanocomposites, which is applied in bulk-heterojunction solar cells. ${ }^{43,44}$ In these solar cells both the CP and the fullerene are photoactive. In the current study, however, only the CP is photoactive, while the nanocarbons act as metallic conductors. On the basis of the above discussion, the question occurs instantaneously: Do conducting polymers behave similarly to inorganic semiconductors in these hybrids, or do the different physical-chemical properties result in different synergistic activity?

In this study, we present the PEC behavior of PEDOT/CNT and PEDOT/graphene nanocomposite photoelectrodes. According to the best of our knowledge, this is the first instance where $\mathrm{CP} /$ nanocarbon composites are studied as photoelectrodes. We investigated the effect of the PEDOT/ nanocarbon ratio and the nanocarbon loading on the PEC behavior. We demonstrated that the high specific surface area and the improved charge carrier transport both contribute to suppressed recombination and consequently higher photocurrent values. Finally, we show that the enhancement is more pronounced compared to the inorganic semiconductor counterparts.

\section{EXPERIMENTAL SECTION}

Materials. Sodium dodecyl sulfate (SDS, Alfa Aesar), sodium sulfate $\left(\mathrm{Na}_{2} \mathrm{SO}_{4}\right.$, VWR), sodium hydrogen carbonate $\left(\mathrm{NaHCO}_{3}, \mathrm{VWR}\right)$ were of analytical grade and used without further purification. Graphene powder was purchased from Elicarb (premium graphene powder), while multiwall carbon nanotubes were purchased from Cheap Tubes USA. Nitrogen $\left(\mathrm{N}_{2}, 99.995 \%\right)$, carbon dioxide $\left(\mathrm{CO}_{2}, 99.995 \%\right)$, and argon ( $\mathrm{Ar}$, 99.999\%) gases were purchased from Messer. The monomer 3,4-ethylenedioxythiophene (EDOT, SigmaAldrich, 97\%) was vacuum-distilled prior to each use. All solutions were prepared using deionized water (Millipore Direct Q3-UV, $18.2 \mathrm{M} \Omega \mathrm{cm}$ ).

Nanocomposite Preparation. Nanocarbons were spraycoated to the supporting electrode surface, which was followed by the subsequent deposition of PEDOT onto the surface of the nanocarbons. This method was favored over co-deposition because in this way a direct contact was formed between the nanocarbon and the supporting electrode surface; therefore the expected enhancement in the charge carrier transport and conductivity can be ensured. ${ }^{42}$ In addition, by employing this two-step process, we could use pristine (i.e., nonoxidized) nanocarbons, which is very important to ensure sufficient conductivity. First, the CNT-containing $\left(c \approx 2 \mathrm{mg} \mathrm{mL}^{-1}\right)$ and the graphene-containing dispersion $\left(c \approx 2 \mathrm{mg} \mathrm{mL}^{-1}\right)$ was spray-coated on a preheated glassy carbon (GC) electrode surface, employing an Alder AD320 type airbrush and a homemade spray-coater robot operated with 1 bar compressed air pressure. The electrodes were heated with a hot plate to 140 ${ }^{\circ} \mathrm{C}$ for the coating process. Then, the thin films were heat treated in an oven at $180{ }^{\circ} \mathrm{C}$. While the graphene layers spent only $30 \mathrm{~min}$ in the oven, the CNT layers were treated for $1 \mathrm{~h}$. This treatment removed the residual traces of the solvent and enhanced the adhesion of the nanocarbon layers to the underlying electrode surface. The precise amount of spraycoated nanocarbons was monitored by a Mettler Toledo XPE26 type analytical microbalance (Figure S2).

Structural and Morphological Characterization. Raman spectroscopic measurements were performed on a DXR Raman microscope using a green laser $(\lambda=532 \mathrm{~nm})$, operating at $5 \mathrm{~mW}$ laser power. For these measurements, 

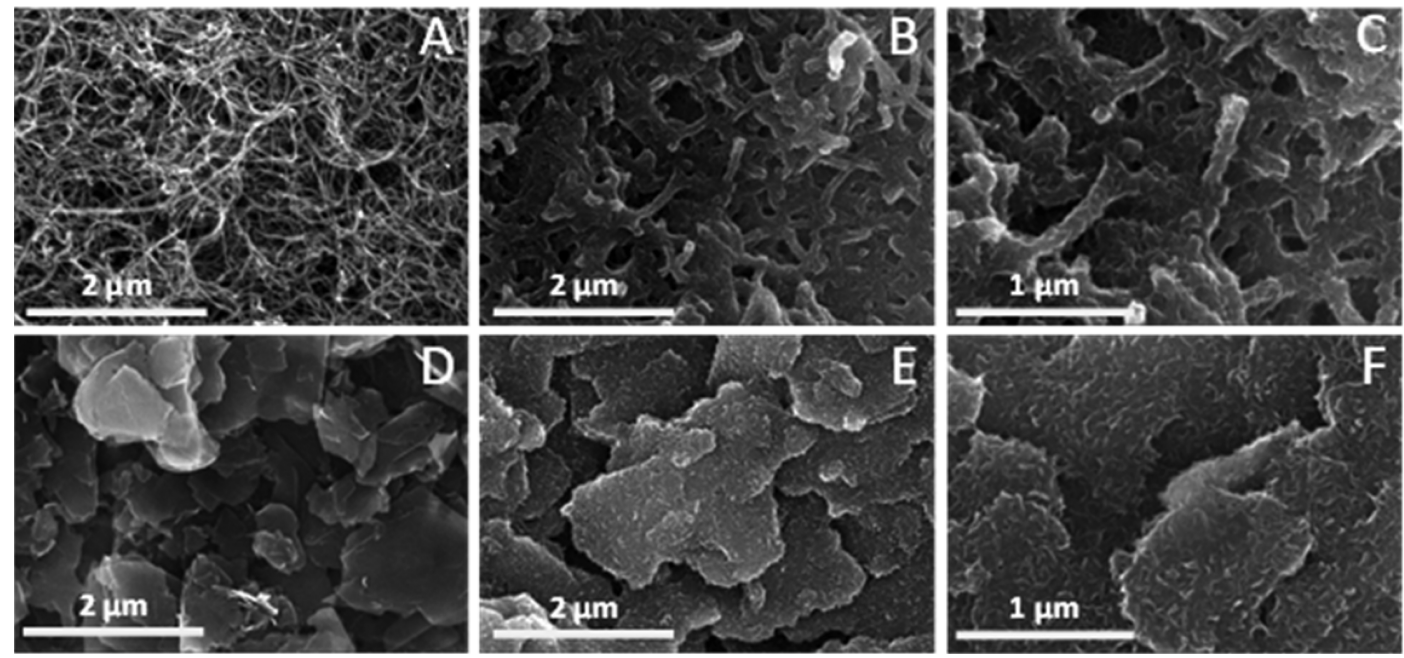

Figure 2. (A) SEM images of a bare CNT layer on GC $\left.\left(m_{\mathrm{CNT}}=60 \mu \mathrm{g} \mathrm{cm}\right)^{-2}\right),(\mathrm{B}, \mathrm{C})$ PEDOT/CNT nanocomposite layer on GC $\left(m_{\mathrm{CNT}}=60 \mu \mathrm{g}\right.$ $\left.\mathrm{cm}^{-2}\right), Q_{\text {pol }}=400 \mathrm{mC} \mathrm{cm}^{-2},(\mathrm{D})$ graphene layer on $\mathrm{GC}\left(m_{\text {graphene }}=110 \mu \mathrm{g} \mathrm{cm}^{-2}\right)$, and $(\mathrm{E}, \mathrm{F}) \mathrm{PEDOT} /$ graphene layer on GC $\left(m_{\text {graphene }}=110 \mu \mathrm{g}\right.$ $\left.\mathrm{cm}^{-2}\right), Q_{\mathrm{pol}}=200 \mathrm{mC} \mathrm{cm}{ }^{-2}$.

nanocarbons were spray-coated on a Au working electrode to exclude the signals originating from the GC electrode surface. Transmission electron microscopic (TEM) images were recorded by using a FEI Tecnai G2 $20 \mathrm{X}$-Twin type instrument, operating at an acceleration voltage of $200 \mathrm{kV}$. A Hitachi S4700 field emission scanning electron microscope (SEM) was operated at an accelerating voltage of $10 \mathrm{kV}$.

(Photo)Electrochemical Measurements. All electrochemical measurements were performed on a Metrohm Autolab PGSTAT302 type potentiostat/galvanostat. The electropolymerization of EDOT was carried out in a classical three-electrode cell setup, including a $\mathrm{Ag} / \mathrm{AgCl} / 3 \mathrm{M} \mathrm{NaCl}$ as reference and a $\mathrm{Pt}$ sheet as a counter electrode. EDOT was electropolymerized from a solution containing 0.05 M SDS and $0.02 \mathrm{M}$ EDOT. To ensure the proper wetting of the nanostructured electrodes, they were pretreated prior to electropolymerization by cycling the potential between 0 and $0.5 \mathrm{~V} 10$ times, applying a sweep rate of $50 \mathrm{mV} \mathrm{s}^{-1}$. As a next step, potentiostatic polymerization was employed at $0.9 \mathrm{~V}$.

Linear sweep photovoltammograms were recorded in a sealed, custom-designed one-compartment, three-electrode quartz cell. The PEDOT and PEDOT/nanocarbon layer on the GC substrate was used as the working electrode, while a Pt sheet and $\mathrm{Ag} / \mathrm{AgCl} / 3 \mathrm{M} \mathrm{NaCl}$ were employed as the counter and reference electrodes, respectively. The applied light source was a Newport LCS-100 type solar simulator operated at full output. The radiation source was placed $5 \mathrm{~cm}$ away from the illuminated working electrode surface $\left(200 \mathrm{~mW} \mathrm{~cm}^{-2}\right.$ flux $)$, which was irradiated through a quartz window. The cell, containing $0.1 \mathrm{M} \mathrm{Na}_{2} \mathrm{SO}_{4}$ electrolyte, was saturated with $\mathrm{Ar}$ by $30 \mathrm{~min}$ of continuous bubbling prior to each measurement. Before the PEC measurements, a potentiostatic pretreatment procedure was applied at $E=-0.9 \mathrm{~V}$ for $3 \mathrm{~min}$ to make sure that PEDOT is fully reduced. The photovoltammograms were recorded using a slow potential sweep $\left(2 \mathrm{mV} \mathrm{s}^{-1}\right)$ in conjunction with periodically interrupted irradiation $(0.1 \mathrm{~Hz})$.

Incident photon-to-charge conversion efficiency (IPCE) measurements were performed on a Newport Quantum Efficiency Measurement System (QEPVSI-B) in a single compartment, three-electrode quartz electrochemical cell. The wavelength range was $350-800 \mathrm{~nm}(\Delta \lambda=10 \mathrm{~nm}$ resolution).
The solution was $0.1 \mathrm{M} \mathrm{Na}_{2} \mathrm{SO}_{4}$ saturated with Ar. The electrodes were held at $-1.0 \mathrm{~V}$ constant potential during the measurements.

Kelvin-Probe Microscopy Coupled UV Ambient Pressure Photoelectron Spectroscopy. Measurements were performed using the KP Technology APSO4 instrument. ${ }^{45}$ First, the contact potential difference (CPD) was measured between the sample and the Kelvin probe after electric equilibrium was reached. A $2 \mathrm{~mm}$ diameter gold alloy-coated tip was vibrated above the sample surface at a constant height $(\sim 1 \mathrm{~mm})$ and amplitude $(0.2 \mathrm{~mm})$, with a constant frequency $(70 \mathrm{~Hz})$. Ambient pressure UV photoelectron spectroscopy (UV-APS), measurements were carried out with a stationary Kelvin-probe tip. The sample surface was illuminated with a 4$5 \mathrm{~mm}$ spot size, variable energy UV light source. The UV light generates an electron cloud from the SC if $h \nu \geq E_{\mathrm{VB}}$. Under atmospheric conditions, this is followed by the formation of secondary ions $\left(\mathrm{N}_{2}^{-}, \mathrm{O}_{2}^{-}\right)$. Then, these ions can be collected by the Kelvin-probe tip; thus a current is measured. In the case of SCs, a cube-root dependence of this current was found from the excitation energy. ${ }^{45}$ The intersection of the baseline and the rise in the cube root of the photoemission current can be then related to the VB of a given SC. Before measurements, the Fermi level of the gold alloy-coated tip was determined by measuring the Fermi level of an $\mathrm{Ag}$ target $\left(E_{\mathrm{Fermi}, \mathrm{Au} \text {-tip }}=4.67\right.$ $\mathrm{eV})$.

Long-Term Photoelectrolysis. Long-term PEC measurements were carried out in a sealed two-compartment cell $\left(V_{\text {solution }}=40 \mathrm{~cm}^{3}\right)$ where the compartments were separated by a Nafion 117 membrane. The working electrode was a PEDOT or PEDOT/nanocarbon modified GC $\left(A=4 \mathrm{~cm}^{2}\right)$, a Pt sheet was applied as a counter and a $\mathrm{Ag} / \mathrm{AgCl} / 3 \mathrm{M} \mathrm{NaCl}$ as a reference electrode while the applied potential was $-0.9 \mathrm{~V}$ during the measurements. The electrodes were pretreated at the same potential for $300 \mathrm{~s}$ without illumination. The $0.1 \mathrm{M}$ $\mathrm{Na}_{2} \mathrm{SO}_{4}$ electrolyte was saturated with $\mathrm{Ar}$ prior to the measurements (constant bubbling for $30 \mathrm{~min}$ ). During the reaction, gas samples were taken at $30,60,90$, and $120 \mathrm{~min}$ via an online detection system, which was coupled to the cathode compartment of the cell. Products in the gas phase were separated with a ShinCarbon ST column and analyzed with a 

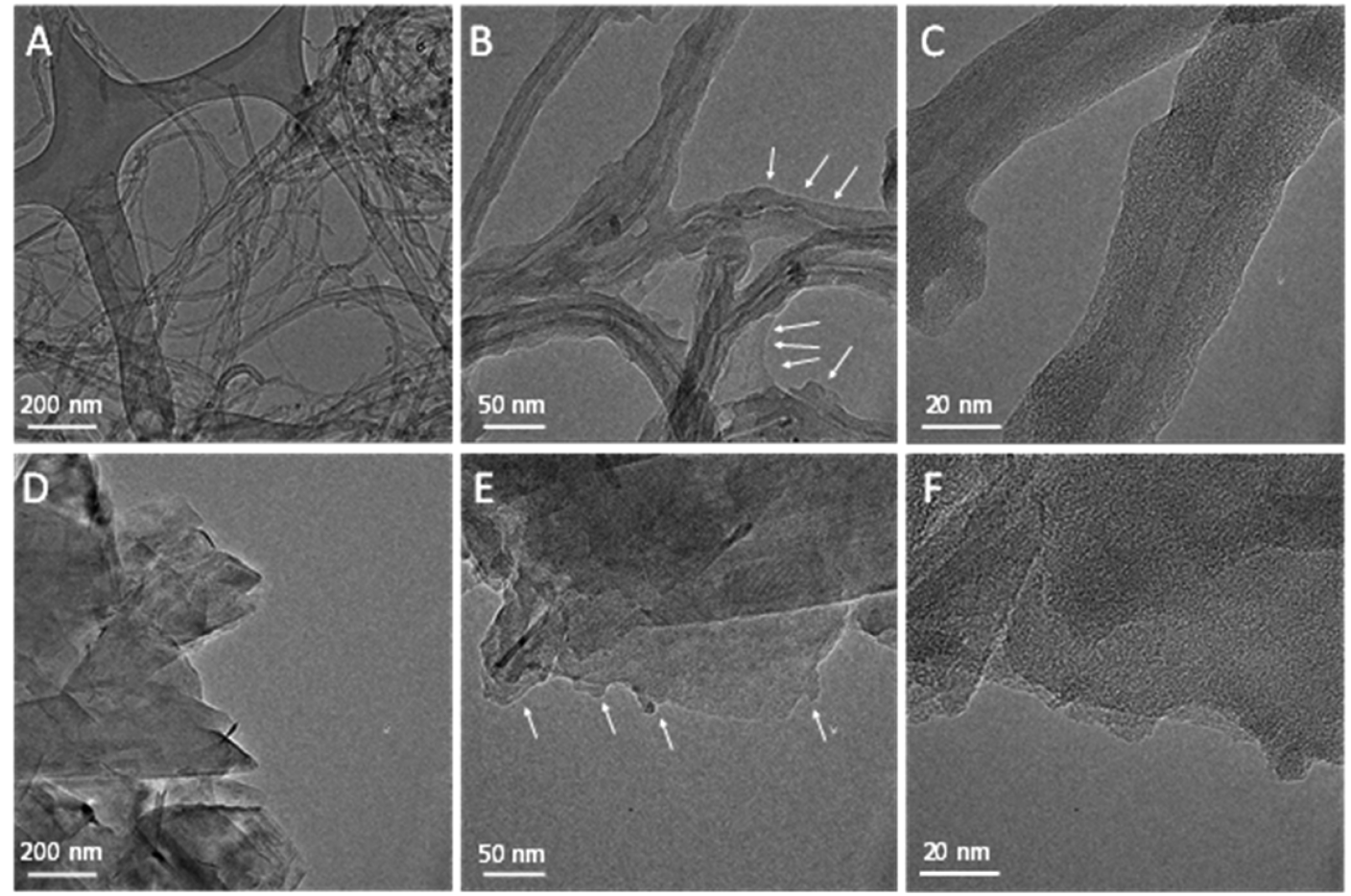

Figure 3. TEM images captured for the (A) bare CNTs, (B, C) PEDOT/CNT layer $\left(m_{\mathrm{CNT}}=60 \mu \mathrm{g} \mathrm{cm}^{-2}, Q_{\mathrm{pol}}=400 \mathrm{mC} \mathrm{cm}^{-2}\right),(\mathrm{D})$ bare graphene, (E, F) PEDOT/graphene $\left(m_{\text {graphene }}=110 \mu \mathrm{g} \mathrm{cm}^{-2}, \mathrm{Q}_{\mathrm{pol}}=200 \mathrm{mC} \mathrm{cm}{ }^{-2}\right)$ nanocomposites. The white arrows highlight the presence of the polymer on the surface of the nanocarbons.

Shimadzu GC-2010 Plus gas chromatograph equipped with a barrier discharge ionization (BID) detector. The optimized parameters were the following: carrier gas, helium; oven program, $T_{\text {start }}=35{ }^{\circ} \mathrm{C}(2.5 \mathrm{~min}), \Delta T_{\text {ramp }}=20^{\circ} \mathrm{C} \mathrm{min}{ }^{-1}, T_{\text {end }}$ $=270{ }^{\circ} \mathrm{C}(3 \mathrm{~min})$; injection temperature $\mathrm{T}=150{ }^{\circ} \mathrm{C}$; linear velocity was controlled by the pressure $p_{\text {start }}=250 \mathrm{kPa}(2.5$ $\min ), \Delta p_{\text {ramp }}=15 \mathrm{kPa} \min ^{-1}, p_{\text {end }}=400 \mathrm{kPa}(7.5 \mathrm{~min})$; and the split ratio was 10 .

\section{RESULTS AND DISCUSSION}

Electrodeposition of PEDOT on the Nanocarbons. After immobilization of the CNT or graphene scaffolds on the GC working electrode surface, PEDOT was electrodeposited with potentiostatic polymerization. Varying the polymerization charge density during the synthesis resulted in nanocomposite layers with different PEDOT/nanocarbon ratio (see an example in Figure S3). In the case of the nanocarbons higher currents flow compared to the bare GC because of the higher surface area of the nanocarbon-coated electrodes. Cyclic voltammograms (CVs) were recorded for each nanocomposite sample in an $\mathrm{Ar}$ saturated $0.1 \mathrm{M} \mathrm{Na}_{2} \mathrm{SO}_{4}$ solution to determine their charge capacitance. The CVs and the charge capacitance vs polymerization charge density curves, collected for the $\mathrm{PEDOT} /$ graphene nanocomposite electrodes, are shown in Figure S4. The linear relationship between the polymerization charge density and the electroactivity of the obtained PEDOT confirmed the continuous growth of the polymer on the nanocarbon support.

Morphological and Structural Characterization. The morphological features of the pristine components and the nanocomposites were investigated with SEM and TEM. Figure 2 shows SEM images of the bare nanocarbons (A, D) and the respective nanocomposite samples $(\mathrm{B}, \mathrm{C}, \mathrm{E}$, and $\mathrm{F})$. The bare PEDOT formed a continuous, granular, sponge-like coating on the GC electrode surface (Figure S5) which is characteristic of the electrodeposited PEDOT when SDS is applied as an electrolyte. ${ }^{46}$ SEM images also confirmed that both the bare CNT and the graphene cover the GC surface completely. The average diameter of the nanotubes was $15 \pm 4 \mathrm{~nm}$ (see also Figure S6 for the size distribution histogram, derived from the SEM measurements), while the average graphene flake size was $1088 \pm 49 \mathrm{~nm}$.

SEM images of a PEDOT/CNT nanocomposite demonstrated that the carbon nanonetwork was entirely covered by the polymer (Figure 2B,C). The thickness of the deposited PEDOT layer can be calculated with the following equation:

$$
d_{\mathrm{PEDOT}}=\frac{d_{\mathrm{CNT}+\mathrm{PEDOT}}-d_{\mathrm{CNT}}}{2}
$$

The histogram, presented in Figure S7, shows that polymer thickness was in the $20-80 \mathrm{~nm}$ range, with an average of $40 \pm$ $11 \mathrm{~nm}$. This observation stands only for the layers, where the polymerization charge density was maintained at $400 \mathrm{mC} \mathrm{cm}^{-2}$, while the amount of the spray-coated CNT was fixed at $60 \mu \mathrm{g}$ $\mathrm{cm}^{-2}$. The layer thickness, however, can be tuned up to an extent, where PEDOT forms a constant layer filling up the gaps between the individual CNTs. Similar observations can be made for the PEDOT/graphene nanocomposites: PEDOT has also coated the surface of the nanoflakes evenly (Figure $2 \mathrm{E}$ and Figure 2F).

TEM images of the bare CNTs and a PEDOT/CNT nanocomposite $\left(m_{\mathrm{CNT}}=60 \mu \mathrm{g} \mathrm{cm}^{-2}, Q_{\mathrm{pol}}=400 \mathrm{mC} \mathrm{cm}{ }^{-2}\right)$ revealed that the polymer completely enfolded the nanotubes (Figure $3 \mathrm{~A}-\mathrm{C}$ ). This was further visualized by HR-TEM images (Figure S8). Additionally, a 10-15 nm thick PEDOT film was spotted around the carbon nanotube. Pristine graphene appeared on the TEM images as large, twodimensional sheets (Figure 3D). As for the nanocomposite, 

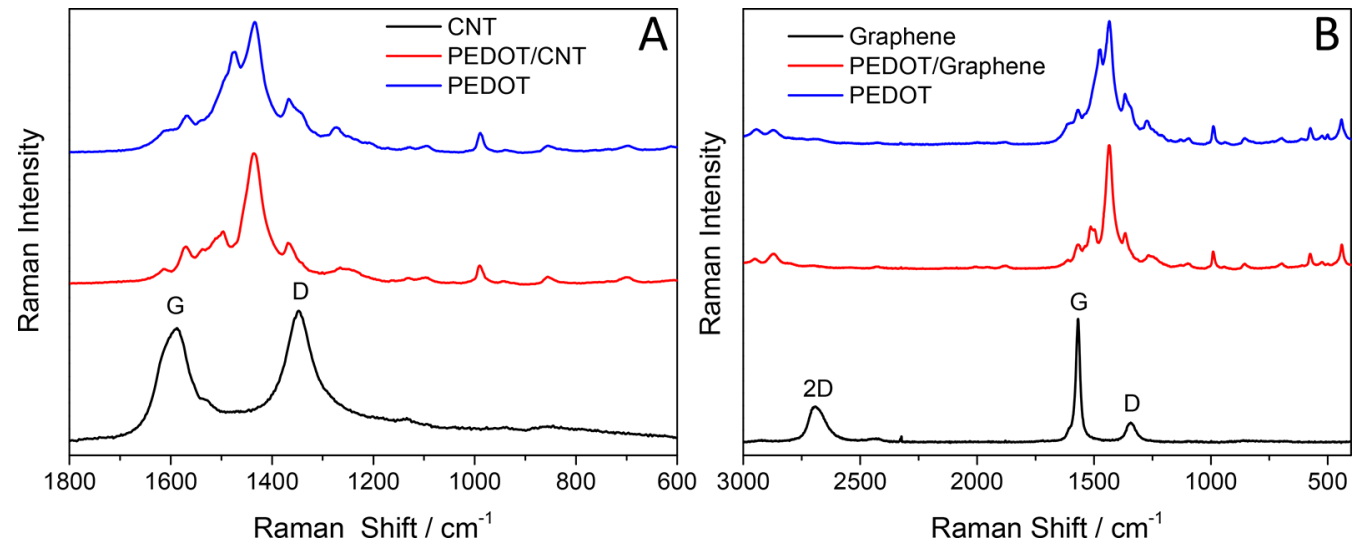

Figure 4. Raman spectra of (A) CNT (black line), PEDOT (blue line), and PEDOT $/ \mathrm{CNT}$ (red line) samples $\left(m_{\mathrm{CNT}}=60 \mu \mathrm{g} \mathrm{cm}{ }^{-2}, Q_{\mathrm{pol}}=400 \mathrm{mC}\right.$ $\left.\mathrm{cm}^{-2}\right)$ and (B) graphene (black line), PEDOT (blue line), and PEDOT/graphene (red line) samples $\left(m_{\text {graphene }}=110 \mu \mathrm{g} \mathrm{cm}{ }^{-2}, Q_{\mathrm{pol}}=200 \mathrm{mC}\right.$ $\left.\mathrm{cm}^{-2}\right)$.
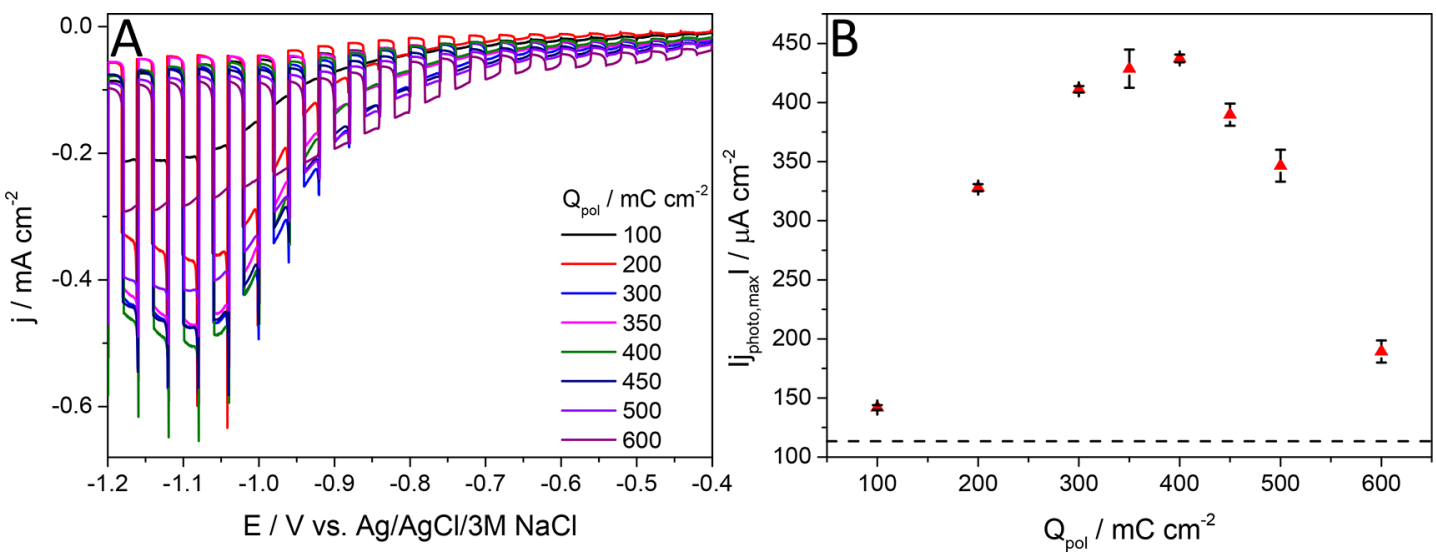

Figure 5. (A) Comparison of the photovoltammograms, recorded in Ar-saturated $0.1 \mathrm{M} \mathrm{Na}_{2} \mathrm{SO}_{4}$ for the nanocomposites prepared with different PEDOT/CNT ratio by varying the polymerization charge density $\left(m_{\mathrm{CNT}}=60 \mu \mathrm{g} \mathrm{cm}^{-2}\right)$. Measurements were carried out applying $2 \mathrm{mV} \mathrm{s}{ }^{-1}$ sweep rate, $0.1 \mathrm{~Hz}$ chopping frequency, and a solar simulator as the light source. (B) Maximum photocurrent vs polymerization charge density plot, calculated from the data presented in part A. The dashed line marks the highest photocurrent, recorded for the best-performing PEDOT photoelectrode.

less sharp and less well-defined edges formed indicating the presence of PEDOT on the surface of the nanoflakes (Figure $3 \mathrm{E}$ and Figure $3 \mathrm{~F}$ ).

To gain further insights into the structural properties of the nanocomposite samples, Raman spectroscopy was employed (Figure 4). The spectrum of the CNT film showed two typical broad bands (black) that are characteristic to all carbon nanomaterials. One of them is centered at $1588 \mathrm{~cm}^{-1}$ (G band), and the other one is at $1347 \mathrm{~cm}^{-1}$ (D band). The spectrum of the bare PEDOT layer is presented in Figure 4A (blue curve). The assignment of the observed bands is presented in the Supporting Information (Table S1), which confirmed the presence of conjugated PEDOT. ${ }^{47,48}$ All these characteristic bands are visible on the spectrum of the PEDOT/CNT nanocomposite without any significant and characteristic shift compared to that of the bare constituents.

The graphene-containing electrodes showed similar trends to the PEDOT/CNT samples (Figure 4B). There are three characteristic bands on the spectrum: a sharp $\mathrm{G}$ band centered at $1570 \mathrm{~cm}^{-1}$ (attributed to the vibration of the $\mathrm{sp}^{2}$ hybridized carbon atoms), the $\mathrm{D}$ band, centered at $1340 \mathrm{~cm}^{-1}$ (corresponding to the $\mathrm{sp}^{3}$ defects in the graphene layers), and the $2 \mathrm{D}$ band, centered at $2689 \mathrm{~cm}^{-1}$ (attributed to the double resonant scattering process from zone-edge phonons). ${ }^{49}$
The small $\mathrm{D} / \mathrm{G}$ ratio $(0.17)$ and the shape and position of the $2 \mathrm{D}$ band suggest that a high-quality, few-layer graphene was applied in this study. ${ }^{50}$ Conclusions that were drawn from the spectrum of the PEDOT/graphene sample are similar to PEDOT/CNT nanocomposites.

Photoelectrochemical Behavior. Given that the various PEC attributes are highly dependent on the morphology and composition of the nanohybrid photoelectrodes, two directions were followed to optimize their performance. First, to find the optimal PEDOT/nanocarbon ratio, the amount of CNT and graphene on the electrode surface was kept constant, while the amount of PEDOT was varied systematically by changing the polymerization charge. After determination of the optimal $\mathrm{PEDOT} /$ nanocarbon ratios (one for $\mathrm{CNT}$ and another for graphene), the effect of carbon loading was investigated. In these experiments, the PEDOT/CNT and PEDOT/graphene ratio was held constant and the amount of the nanocarbon (and thus the nanocomposite) was varied. The polymer content has a major effect on the maximum photocurrent (Figure 5): at ideal PEDOT/CNT ratio, almost 4 times higher photocurrents were recorded compared to the pristine PEDOT layers (see dashed line in Figure 5B). When less polymer was deposited on the conducting CNT network, the photocurrents were notably inferior, together with the cases when the polymerization 

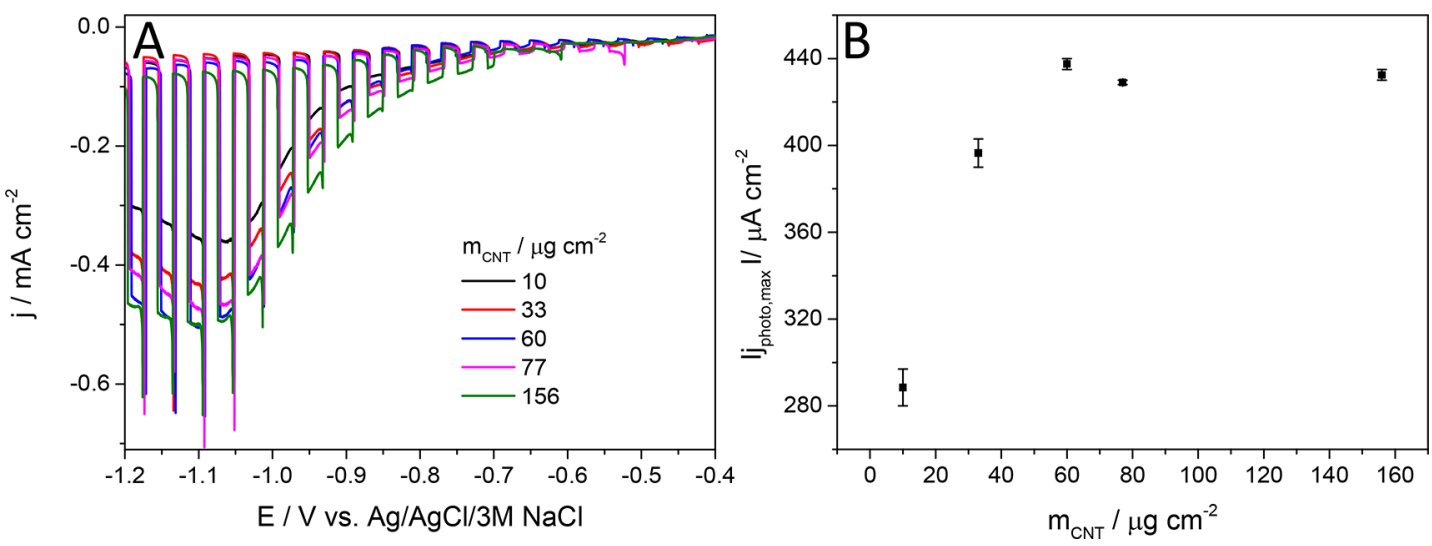

Figure 6. (A) Comparison of the photovoltammograms, recorded in Ar-saturated $0.1 \mathrm{M} \mathrm{Na}_{2} \mathrm{SO}_{4}$ for the nanocomposites prepared with the same PEDOT/CNT ratio but varying the CNT loading. (B) Maximum photocurrent vs spray-coated CNT mass plot, calculated from the data presented in part A. Measurements were carried out applying $2 \mathrm{mV} \mathrm{s}^{-1}$ sweep rate, $0.1 \mathrm{~Hz}$ chopping frequency, and a solar simulator as a light source.
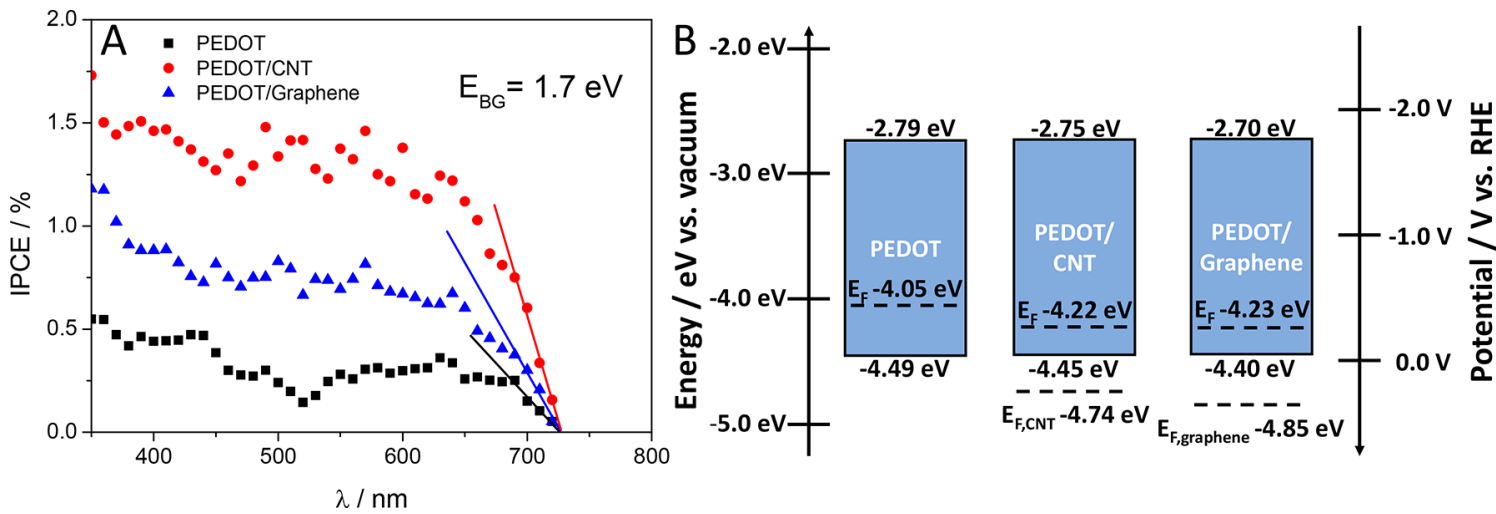

Figure 7. (A) IPCE curves recorded for a PEDOT, a PEDOT/CNT, and a PEDOT/graphene photoelectrode in $0.1 \mathrm{M} \mathrm{Na}_{2} \mathrm{SO}_{4}$ saturated with Ar at $-1.0 \mathrm{~V}$ constant potential. (B) Band diagrams.

charge density exceeded the optimal value. When the amount of polymer was less than the optimal value, the surface of the nanotubes was not covered completely, and the electrodeposited polymer layer was too thin to absorb the illuminating light completely. When the PEDOT layer was thicker (more than $100 \mathrm{mC} \mathrm{cm}^{-2}$ ), the PEC properties of the bulk polymer dominated, and the photocurrents approached the values measured for the pristine PEDOT.

As the next step, the PEDOT/CNT ratio was held constant (at the one which gave the highest photocurrents) and the effect of the nanocomposite loading was investigated (Figure 6). The photocurrent reached its maximum value at a CNT loading of $60 \mu \mathrm{g} \mathrm{cm}^{-2}$. If the spray-coated amount of CNT was less, the effect of the CNT network could not prevailed, because only a very thin film formed on the GC surface, leading to smaller photocurrents. If the spray-coated mass of the CNTs was above $60 \mu \mathrm{g} \mathrm{cm}^{-2}$, the photocurrent values reached a plateau around the value measured previously for the best performing PEDOT/CNT nanocomposite photoelectrode. As for the graphene containing electrodes (Figures S9 and S10), some differences can be pointed out: (i) the highest obtainable photocurrent was approximately 1.5 times smaller compared to the CNT case $\left(293 \mu \mathrm{A} \mathrm{cm} \mathrm{cm}^{-2}\right.$ vs $\left.437 \mu \mathrm{A} \mathrm{cm} \mathrm{cm}^{-2}\right)$, but (ii) significantly less polymer was needed to reach the optimal $\mathrm{PEDOT} /$ graphene composition $\left(200 \mathrm{mC} \mathrm{cm}^{-2}\right)$.

Figure 7A shows the photoaction spectra of PEDOT and the best performing nanocomposite samples. Before these measurements, we controlled that the photocurrent was a linear function of the light intensity in the $10-200 \mathrm{~mW} \mathrm{~cm}^{-2}$ range (not shown here). The electrochemically active surface area of the nanocarbons was set to be identical (loadings: $60 \mu \mathrm{g} \mathrm{cm}^{-2}$ for CNT and $130 \mu \mathrm{g} \mathrm{cm}^{-2}$ for graphene). The characteristics of the three curves are similar, and the order of the maximum incident photon to current conversion efficiencies was in line with the photovoltammetry data (i.e., the highest values were measured for PEDOT/CNT, and the integrated current densities were equal to those measured during the photovoltammetry scans). The bandgap was calculated by a linear fitting to the cutoff region of each spectrum and extrapolating to the wavelength axis. A bandgap energy of $1.7 \mathrm{eV}$ was estimated, which was similar for all three systems and is in good agreement with the literature values. ${ }^{52,53}$ This is a direct evidence that the absorption range has not broadened in the case of the nanocomposites compared to the bare PEDOT; therefore it cannot be accounted for the enhanced PEC performance. Electrochemical impedance spectroscopy revealed that by electrodepositing PEDOT on the nanocarbon networks, the electric conductivity improved (see detailed analysis in the Supporting Information). This resulted in better charge carrier transport and suppressed charge carrier recombination, which explains the higher observed photocurrents in the case of the PEDOT/CNT and PEDOT/graphene layers.

To determine the Fermi levels and to construct band energy diagrams for both PEDOT and the PEDOT/nanocarbon electrodes, Kelvin probe microscopy measurements were carried out coupled with ambient pressure photoelectron 

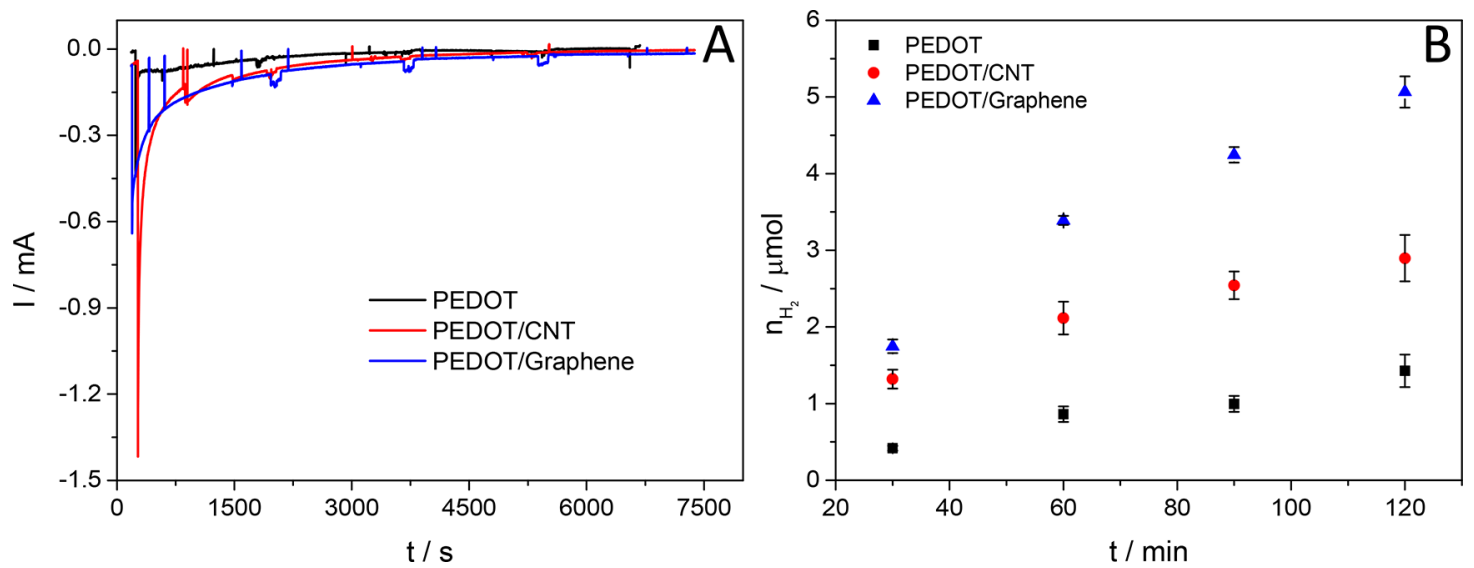

Figure 8. (A) Long-term chronoamperometry data registered for PEDOT, PEDOT/CNT, and PEDOT/graphene layers at $E=-1.0 \mathrm{~V}$ potential (vs $\mathrm{Ag} / \mathrm{AgCl}$ ) in $0.1 \mathrm{M} \mathrm{Na}_{2} \mathrm{SO}_{4}$ saturated with Ar. A solar simulator was used as a light source. (B) Amount of $\mathrm{H}_{2}$ formed during the photoelectrolysis experiments, presented in part A.

spectroscopy. ${ }^{45}$ Similar valence band energy $\left(E_{\mathrm{VB}}\right)$ values were found for all three systems $(-4.49 \mathrm{eV}$ for PEDOT, $-4.45 \mathrm{eV}$ for PEDOT/CNT, and $-4.40 \mathrm{eV}$ for PEDOT/graphene; see the corresponding APS data in Figure S11A-C). Fermi levels were calculated from the CPD measurements (Figure S11D-F, described in detail in the Experimental Section). The $E_{\mathrm{F}}$ values fall close to the $E_{\mathrm{VB}}$ of all three systems, which is characteristic of p-type SCs. ${ }^{51}$ Additionally, by electrodepositing PEDOT to the surface of both CNTs and graphene, $E_{\mathrm{F}}$ slightly shifts toward more negative energies. This trend can be explained by the slightly more negative $E_{\mathrm{F}}$ values, calculated for the bare $\operatorname{CNT}\left(E_{\mathrm{F}, \mathrm{CNT}}=-4.74 \mathrm{eV}\right)$ and graphene $\left(E_{\mathrm{F}, \text { graphene }}=-4.85\right.$ $\mathrm{eV}$ ), moving $E_{\mathrm{F} \text {,nanocomposite }}$ in between the $E_{\mathrm{F}}$ values, measured for its pristine counterparts (i.e., Fermi level equilibration). After obtaining both $E_{\mathrm{VB}}$ and $E_{\mathrm{F}}$ for all three systems, conduction band energies $\left(E_{\mathrm{CB}}\right)$ were calculated using the optical bandgap, determined from the UV-vis and IPCE measurements previously. Finally, band diagrams were constructed (Figure 7B).

Long-Term Photoelectrolysis. The photostability of both the bare PEDOT and the PEDOT/nanocarbon photoelectrodes was investigated by long-term chronoamperometry measurements. In the case of the PEDOT layers, a photocurrent transient evolves right after illuminating the electrode surface, which is followed by a rather intensive decay in the values of the measured photocurrents. The photocurrent reached its steady-state value after around 50-60 min (10$15 \mu \mathrm{A}$, black curve in Figure 8A). Similar transient characteristics can be identified on the curves, measured for both the $\mathrm{PEDOT} / \mathrm{CNT}$ and the PEDOT/graphene layers (red and blue curves in Figure 8A), but the values of the steady-state photocurrents are higher, compared to the pristine PEDOT $(\sim 20-30 \mu \mathrm{A})$.

To quantify the evolved product(s) during the long-term PEC measurements, gas chromatographic analysis was performed using a BID detector. Only hydrogen was identified in the gas phase for each system, the amount of which gradually increased during the photoelectrolysis (Figure 8B). The weaker stability of the PEDOT/CNT layers was also reflected in the smaller amount of the hydrogen evolved during the experiments, compared to the PEDOT/graphene system. The Faradaic efficiency was between $80 \%$ and $100 \%$ in all cases.

\section{CONCLUSIONS}

The effect of CNT and graphene was investigated on the PEC behavior of PEDOT. The polymer was electrodeposited on the surface of both spray-coated nanocarbons, which allowed the precise control of the amount of PEDOT present on the electrode surface. The effects of the PEDOT/nanocarbon ratio and the amount of the spray-coated CNT and graphene on the achieved photocurrent values were explored. At the optimal composition, 4 times higher photocurrents were harvested in the case of the PEDOT/CNT system, compared to the pristine PEDOT, while this ratio was 2.5 in the case of the PEDOT/ graphene photoelectrodes. Kelvin-probe measurements indicated a slight shift in the Fermi level of PEDOT in the hybrid configuration, which confirmed the intimate contact between the polymer and the nanocarbon supports. According to the EIS measurements, both nanocarbons significantly enhanced the conductivity of the nanocomposites compared to the bare PEDOT layers. These interconnected CNT and graphene networks facilitated the photogenerated charge carrier transport toward both to the surface of the glassy carbon electrode and to the electrode/electrolyte interface resulting in suppressed charge carrier recombination and thus higher harvested photocurrents. Hydrogen gas was the only detectable product in the gas phase for all systems, which evolved with a Faradaic efficiency, close to $100 \%$.

\section{ASSOCIATED CONTENT}

\section{S Supporting Information}

The Supporting Information is available free of charge on the ACS Publications website at DOI: 10.1021/acs.jpcc.8b00145.

GC-BID data, preparation of the photoelectrodes, additional SEM and HR-TEM images, assignment of the characteristic Raman bands of PEDOT, additional photovoltammetry data, CPD and APS measurements, EIS data (PDF)

\section{AUTHOR INFORMATION}

\section{Corresponding Author}

*E-mail: janaky@chem.u-szeged.hu.

ORCID

Csaba Janáky: 0000-0001-5965-5173 


\section{Notes}

The authors declare no competing financial interest.

\section{ACKNOWLEDGMENTS}

This project has received funding from the European Research Council (ERC) under the European Union's Horizon 2020 research and innovation program (Grant Agreement 716539). This work was partly supported by Project GINOP 2.3.2/201513. A.K. and D. H. also acknowledge the support of the New National Excellence Program of the Ministry of Human Capacities (Grant UNKP-17-3). The authors are thankful to Gergely Ferenc Samu for his help during the Kelvin probe microscopy measurements and also to Dr. Bíborka JanákyBohner (University of Szeged, Hungary) for her support during the manuscript preparation.

\section{REFERENCES}

(1) Roger, I.; Shipman, M. A.; Symes, M. D. Earth-Abundant Catalysts for Electrochemical and Photoelectrochemical Water Splitting. Nat. Rev. Chem. 2017, 1, 0003.

(2) White, J. L.; Baruch, M. F.; Pander, J. E.; Hu, Y.; Fortmeyer, I. C.; Park, J. E.; Zhang, T.; Liao, K.; Gu, J.; Yan, Y.; et al. Light-Driven Heterogeneous Reduction of Carbon Dioxide: Photocatalysts and Photoelectrodes. Chem. Rev. 2015, 115, 12888-12935.

(3) Rajeshwar, K.; Thomas, A.; Janáky, C. Photocatalytic Activity of Inorganic Semiconductor Surfaces: Myths, Hype, and Reality. J. Phys. Chem. Lett. 2015, 6, 139-147.

(4) Kormányos, A.; Thomas, A.; Huda, M. N.; Sarker, P.; Liu, J. P.; Poudyal, N.; Janáky, C.; Rajeshwar, K. Solution Combustion Synthesis, Characterization, and Photoelectrochemistry of $\mathrm{CuNb}_{2} \mathrm{O}_{6}$ and $\mathrm{ZnNb}_{2} \mathrm{O}_{6}$ Nanoparticles. J. Phys. Chem. C 2016, 120, 16024-16034.

(5) Goeppert, A.; Czaun, M.; Surya Prakash, G. K.; Olah, G. A. Air as the Renewable Carbon Source of the Future: An Overview of $\mathrm{CO}_{2}$ Capture from the Atmosphere. Energy Environ. Sci. 2012, 5, 78337853.

(6) Kumar, B.; Llorente, M.; Froehlich, J.; Dang, T.; Sathrum, A.; Kubiak, C. P. Photochemical and Photoelectrochemical Reduction of $\mathrm{CO}_{2}$. Annu. Rev. Phys. Chem. 2012, 63, 541-569.

(7) Kohler, A.; Bassler, H. The Electronic Structure of Organic Semiconductors. In Electronic Processes in Organic Semiconductors; Wiley-VCH: Weinheim, Germany, 2015; Vol. 1, pp 1-3.

(8) Kaneko, M.; Nakamura, H. Photoresponse of a Liquid Junction Polyaniline Film. J. Chem. Soc., Chem. Commun. 1985, 104, 346-347.

(9) Kaneko, M.; Okuzumi, K.; Yamada, A. Photocurrent Generation by a Liquid-Junction Poly(pyrrole) Film. J. Electroanal. Chem. Interfacial Electrochem. 1985, 183, 407-410.

(10) Kilmartin, P. A.; Wright, G. A. Photoelectrochemistry and Spectroscopy of Substituted Polyanilines. Synth. Met. 1999, 104, 145156.

(11) Kilmartin, P. A.; Wright, G. A. Photoeffects to Characterise Polypyrrole Electrodes and Bilayers with Polyaniline. Electrochim. Acta 2001, 46, 2787-2794.

(12) Upadhyay, D. N.; Bharathi, S.; Yegnaraman, V.; Rao, G. P. Photoelectrochemical and Electrochemical Behaviour of Gold Electrode Modified with Bilayers of Polypyrrole and Polyaniline. Sol. Energy Mater. Sol. Cells 1995, 37, 307-314.

(13) Kalaji, M.; Nyholm, L.; Peter, L. M.; Rudge, A. J. Photoelectrochemical Properties of Polyaniline Films. J. Electroanal. Chem. Interfacial Electrochem. 1991, 310, 113-126.

(14) Shen, P. K.; Tian, Z. Q. Photoelectrochemical Behavior of Polyaniline in the Presence of Redox Couple and Electron Acceptor. Electrochim. Acta 1989, 34, 1611-1613.

(15) Desilvestro, J.; Haas, O. Electrocatalytic Behavior of Polyaniline in the Dark and under Illumination. Electrochim. Acta 1991, 36, 361367.
(16) Genies, E. M.; Lapkowski, M. Influence of Light on the Electrochemical Behaviour of Polyaniline Films. Synth. Met. 1988, 24, 69-76.

(17) Hursán, D.; Kormányos, A.; Rajeshwar, K.; Janáky, C. Polyaniline Films Photoelectrochemically Reduce $\mathrm{CO}_{2}$ to Alcohols. Chem. Commun. 2016, 52, 8858-8861.

(18) Martini, M.; De Paoli, M.-A. Action Spectra of EE and SE Illuminated Polypyrrole-Dodecylsulphate Films in Aqueous Solutions. Sol. Energy Mater. Sol. Cells 2000, 60, 73-83.

(19) Miquelino, F. L. C.; De Paoli, M.-A.; Geniès, E. M. Photoelectrochemical Response in Conducting Polymer Films. Synth. Met. 1994, 68, 91-96.

(20) Micaroni, L.; De Paoli, M.-A. Photoelectrochemistry of Poly(3Methylthiophene), I: Surface Morphology and Thickness Effect. Sol. Energy Mater. Sol. Cells 1996, 43, 79-91.

(21) Semenikhin, O.; Ovsyannikova, E.; Ehrenburg, M.; Alpatova, N.; Kazarinov, V. Electrochemical and Photoelectrochemical Behaviour of Polythiophenes in Non-Aqueous Solutions. J. Electroanal. Chem. 2000, 494, 1-11.

(22) Bornoz, P.; Prévot, M. S.; Yu, X.; Guijarro, N.; Sivula, K. Direct Light-Driven Water Oxidation by a Ladder-Type Conjugated Polymer Photoanode. J. Am. Chem. Soc. 2015, 137, 15338-15341.

(23) Winther-Jensen, B.; Winther-Jensen, O.; Forsyth, M.; MacFarlane, D. R. High Rates of Oxygen Reduction over a Vapor Phase-Polymerized PEDOT Electrode. Science 2008, 321, 671-674.

(24) Xia, J.; Masaki, N.; Lira-Cantu, M.; Kim, Y.; Jiang, K.; Yanagida, S. Influence of Doped Anions on Poly(3,4-Ethylenedioxythiophene) as Hole Conductors for Iodine-Free Solid-State Dye-Sensitized Solar Cells. J. Am. Chem. Soc. 2008, 130, 1258-1263.

(25) Xiao, Y.; Han, G.; Wu, J.; Lin, J. Efficient Bifacial Perovskite Solar Cell Based on a Highly Transparent Poly(3,4-Ethylenedioxythiophene) as the p-Type Hole-Transporting Material. J. Power Sources 2016, 306, 171-177.

(26) Kim, J.; Koh, J. K.; Kim, B.; Ahn, S. H.; Ahn, H.; Ryu, D. Y.; Kim, J. H.; Kim, E. Enhanced Performance of $\mathrm{I}_{2}$-Free Solid-State DyeSensitized Solar Cells with Conductive Polymer up to 6.8\%. Adv. Funct. Mater. 2011, 21, 4633-4639.

(27) Xia, J.; Masaki, N.; Lira-Cantu, M.; Kim, Y.; Jiang, K.; Yanagida, S. Effect of Doping Anions' Structures on Poly(3,4-Ethylenedioxythiophene) as Hole Conductors in Solid-State Dye-Sensitized Solar Cells. J. Phys. Chem. C 2008, 112, 11569-11574.

(28) Zhang, J.; Yang, L.; Shen, Y.; Park, B.-W.; Hao, Y.; Johansson, E. M. J.; Boschloo, G.; Kloo, L.; Gabrielsson, E.; Sun, L.; et al. Poly(3,4Ethylenedioxythiophene) Hole-Transporting Material Generated by Photoelectrochemical Polymerization in Aqueous and Organic Medium for All-Solid-State Dye-Sensitized Solar Cells. J. Phys. Chem. C 2014, 118, 16591-16601.

(29) Olivier, Y.; Niedzialek, D.; Lemaur, V.; Pisula, W.; Müllen, K.; Koldemir, U.; Reynolds, J. R.; Lazzaroni, R.; Cornil, J.; Beljonne, D. High-Mobility Hole and Electron Transport Conjugated Polymers: How Structure Defines Function. Adv. Mater. 2014, 26, 2119-2136.

(30) Wei, Q.; Mukaida, M.; Naitoh, Y.; Ishida, T. Morphological Change and Mobility Enhancement in PEDOT:PSS by Adding CoSolvents. Adv. Mater. 2013, 25, 2831-2836.

(31) DeLongchamp, D. M.; Vogt, B. D.; Brooks, C. M.; Kano, K.; Obrzut, J.; Richter, C. A.; Kirillov, O. A.; Lin, E. K. Influence of a Water Rinse on the Structure and Properties of Poly(3,4Ethylenedioxythiophene):Poly(styrene Sulfonate) Films. Langmuir 2005, 21, 11480-11483.

(32) Janáky, C.; Kecsenovity, E.; Rajeshwar, K. Electrodeposition of Inorganic Oxide/Nanocarbon Composites: Opportunities and Challenges. ChemElectroChem 2016, 3, 181-192.

(33) Chauhan, A. K.; Gupta, S. K.; Taguchi, D.; Manaka, T.; Jha, P.; Veerender, P.; Sridevi, C.; Koiry, S. P.; Gadkari, S. C.; Iwamoto, M. Enhancement of the Carrier Mobility of Conducting Polymers by Formation of Their Graphene Composites. RSC Adv. 2017, 7, 1191311920. 
(34) Lightcap, I. V.; Kamat, P. V. Fortification of CdSe Quantum Dots with Graphene Oxide. Excited State Interactions and Light Energy Conversion. J. Am. Chem. Soc. 2012, 134, 7109-7116.

(35) Radich, J. G.; Krenselewski, A. L.; Zhu, J.; Kamat, P. V. Is Graphene a Stable Platform for Photocatalysis? Mineralization of Reduced Graphene Oxide With UV-Irradiated $\mathrm{TiO}_{2}$ Nanoparticles. Chem. Mater. 2014, 26, 4662-4668.

(36) Kecsenovity, E.; Endrődi, B.; Pápa, Z.; Hernádi, K.; Rajeshwar, K.; Janáky, C. Decoration of Ultra-Long Carbon Nanotubes with $\mathrm{Cu}_{2} \mathrm{O}$ Nanocrystals: A Hybrid Platform for Enhanced Photoelectrochemical $\mathrm{CO}_{2}$ Reduction. J. Mater. Chem. A 2016, 4, 31393147.

(37) Lightcap, I. V.; Kamat, P. V. Graphitic Design: Prospects of Graphene-Based Nanocomposites for Solar Energy Conversion, Storage, and Sensing. Acc. Chem. Res. 2013, 46, 2235-2243.

(38) Du, A.; Ng, Y. H.; Bell, N. J.; Zhu, Z.; Amal, R.; Smith, S. C. Hybrid Graphene/Titania Nanocomposite: Interface Charge Transfer, Hole Doping, and Sensitization for Visible Light Response. J. Phys. Chem. Lett. 2011, 2, 894-899.

(39) Williams, G.; Seger, B.; Kamat, P. V. $\mathrm{TiO}_{2}$-Graphene Nanocomposites. UV-Assisted Photocatalytic Reduction of Graphene Oxide. ACS Nano 2008, 2, 1487-1491.

(40) Vietmeyer, F.; Seger, B.; Kamat, P. V. Anchoring ZnO Particles on Functionalized Single Wall Carbon Nanotubes. Excited State Interactions and Charge Collection. Adv. Mater. 2007, 19, 2935-2940.

(41) Kecsenovity, E.; Endrődi, B.; Tóth, P. S.; Zou, Y.; Dryfe, R. A. W.; Rajeshwar, K.; Janáky, C. Enhanced Photoelectrochemical Performance of Cuprous Oxide/Graphene Nanohybrids. J. Am. Chem. Soc. 2017, 139, 6682-6692.

(42) Janáky, C.; Rajeshwar, K. The Role of (Photo)electrochemistry in the Rational Design of Hybrid Conducting Polymer/semiconductor Assemblies: From Fundamental Concepts to Practical Applications. Prog. Polym. Sci. 2015, 43, 96-135.

(43) Salatelli, E.; Marinelli, M.; Lanzi, M.; Zanelli, A.; Dell'Elce, S.; Liscio, A.; Gazzano, M.; Di Maria, F. Bulk Heterojunction Solar Cells: The Role of Alkyl Side Chain on Nanoscale Morphology of Sulfur Overrich Regioregular Polythiophene/Fullerene Blends. J. Phys. Chem. C 2018, 122, 4156-4164.

(44) Moulé, A. J.; Allard, S.; Kronenberg, N. M.; Tsami, A.; Scherf, U.; Meerholz, K. Effect of Polymer Nanoparticle Formation on the Efficiency of Polythiophene Based "Bulk-Heterojunction" Solar Cells. J. Phys. Chem. C 2008, 112, 12583-12589.

(45) Baikie, I. D.; Grain, A. C.; Sutherland, J.; Law, J. Ambient Pressure Photoemission Spectroscopy of Metal Surfaces. Appl. Surf. Sci. 2014, 323, 45-53.

(46) Cho, S. H.; Lee, H. J.; Ko, Y.; Park, S. M. Electrochemistry of Conductive Polymers 47: Effects of Solubilizers on 3,4-Ethylenedixoythiophene Oxidation in Aqueous Media and Properties of Resulting Films. J. Phys. Chem. C 2011, 115, 6545-6553.

(47) Sakmeche, N.; Aaron, J. J.; Fall, M.; Aeiyach, S.; Jouini, M.; Lacroix, J. C.; Lacaze, P. C. Anionic Micelles; a New Aqueous Medium

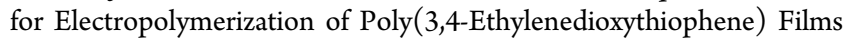
on Pt Electrodes. Chem. Commun. 1996, 2723-2724.

(48) Garreau, S.; Louarn, G.; Buisson, J.; Froyer, G.; Lefrant, S. In Situ Spectroelectrochemical Raman Studies of Poly(3, 4-Ethylenedioxythiophene) (PEDT). Macromolecules 1999, 32, 6807-6812.

(49) Chen, X.; Meng, F.; Zhou, Z.; Tian, X.; Shan, L.; Zhu, S.; Xu, X.; Jiang, M.; Wang, L.; Hui, D.; et al. One-Step Synthesis of Graphene/ Polyaniline Hybrids by in Situ Intercalation Polymerization and Their Electromagnetic Properties. Nanoscale 2014, 6, 8140-8148.

(50) Ferrari, A. C.; Basko, D. M. Raman Spectroscopy as a Versatile Tool for Studying the Properties of Graphene. Nat. Nanotechnol. 2013, $8,235-246$

(51) Rajeshwar, K. In Electron Transfer in Chemistry; Balzani, V., Ed.; Wiley-VCH Verlag GmbH: Weinheim, Germany, 2001.

(52) Chen, X.; Inganäs, O. Three-Step Redox in Polythiophenes: Evidence from Electrochemistry at an Ultramicroelectrode. J. Phys. Chem. 1996, 100, 15202-15206.
(53) Ghosh, S.; Kouame, N. A.; Remita, S.; Ramos, L.; Goubard, F.; Aubert, P.-H.; Dazzi, A.; Deniset-Besseau, A.; Remita, H. Visible-Light Active Conducting Polymer Nanostructures with Superior Photocatalytic Activity. Sci. Rep. 2015, 5, 18002. 